\title{
ChemComm
}

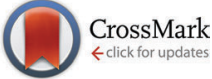

Cite this: Chem. Commun., 2015, 51, 7313

Received 11th January 2015

Accepted 24th March 2015

DOI: $10.1039 / \mathrm{c} 5 \mathrm{cc00255a}$

www.rsc.org/chemcomm

\section{Patterning of polymer brushes made easy using titanium dioxide: direct and remote photocatalytic lithography $\dagger$}

\author{
G. Panzarasa, $\ddagger^{\star^{a}}$ G. Soliveri, $\ddagger^{\text {bc }}$ K. Sparnacci ${ }^{a}$ and S. Ardizzone ${ }^{b c}$
}

\begin{abstract}
Photocatalytic lithography is proved for the realization of micropatterned polymer brushes. Initiator-functionalized titanium dioxide or silicon surfaces are respectively exposed directly to near-UV light through a photomask (direct approach) or through a transparent photoactive $\mathrm{TiO}_{2}$ film (remote approach). Initiator patterns are then amplified as polymer brushes with SI-ATRP. Features down to $10 \mu \mathrm{m}$ could be obtained using simple equipment. The process is intrinsically parallel, has high throughput and scalable to wafer size, making it powerful for microfabrication purposes.
\end{abstract}

Polymer brushes are surface-tethered, highly-stretched polymer chains. They exhibit excellent robustness and well-organized chain conformation, which endow superior control over several surface properties such as morphology, grafting density and chemical composition. ${ }^{1-3}$ Patterned polymer brushes ${ }^{4,5}$ are versatile building blocks for micro-fabrication and controlled assembly of small particles, ${ }^{6}$ sensors/biosensors and actuators,${ }^{7-15}$ drug delivery systems,${ }^{16}$ electronic devices, ${ }^{17}$ anti-biofouling coatings, ${ }^{18}$ and biocompatible scaffolds. ${ }^{19}$ In general they are efficient means to confer smart, stimuli-responsive behavior to surfaces and interphases. ${ }^{20-22}$

By a combination of lithographic tools and surface-initiated polymerization ("grafting-from", as opposed to "grafting to", which relies on the adsorption of the preformed polymer), ${ }^{23,24}$ microand nanoscale-complex architectures can be readily built from suitable self-assembled monolayers (SAMs). ${ }^{25-28}$ SAMs are ordered arrays of molecules chemisorbed at a surface. ${ }^{29}$ If they are composed by polymerization initiators, chains can grow directly from them.

\footnotetext{
${ }^{a}$ Dipartimento di Scienze e Innovazione Tecnologica, Università del Piemonte Orientale "Amedeo Avogadro", Viale T. Michel 11, 15100 Alessandria, Italy. E-mail: guido.panzarasa@unipmn.it

${ }^{b}$ Dipartimento di Chimica, Università degli Studi di Milano, Via Golgi 19, 20133 Milano, Italy.E-mail: guido.soliveri@unimi.it

${ }^{c}$ Consorzio Interuniversitario Nazionale per la Scienza e Tecnologia dei Materiali (INSTM), Via Giusti 9, 50121 Firenze, Italy

$\dagger$ Electronic supplementary information (ESI) available. See DOI: 10.1039/ c5cc00255a

\$ These authors contributed equally.
}

Eventually, if the SAMs are patterned, patterned polymer brushes will be obtained.

The expertise to master the patterning ${ }^{30}$ is crucial in order to realize devices with applications ranging from biotechnology ${ }^{31}$ to electronics. ${ }^{32}$ Patterning has been accomplished using colloidal lithography, ${ }^{33,34}$ micro-contact printing, ${ }^{35,36}$ electron beam lithography ${ }^{37}$ scanning probe ${ }^{38}$ or near field lithography, ${ }^{39}$ conventional photolithography (with the use of photoresists ${ }^{40,41}$ ) and SAM photolithography. ${ }^{42,43}$ The latter typically requires highintensity UV sources ${ }^{6,44-46}$ (e.g. deep-UV and vacuum-UV $)^{47,48}$ or highly focused beams (UV-lasers). ${ }^{49}$

There is a significant demand for more affordable and facile lithographic techniques, which should update the present technologies ${ }^{50}$ to reliably pattern polymer brushes at the wafer scale ${ }^{51}$ with high resolution micrometric and sub-micrometric features. Here, for the first time, we describe how this challenge can be successfully addressed by taking advantage of titanium dioxide photocatalytic properties. To date, this technique has been used mostly to build hydrophilic/hydrophobic patterns. ${ }^{52,53}$

$\mathrm{TiO}_{2}$ is one of the major protagonists in nanotechnology. It is inexpensive and non-toxic; its surface is biocompatible and can be functionalized using established chemistries. ${ }^{54}$ The oxide is an intrinsic semiconductor whose photochemical and photophysical properties have had great relevance both in fundamental ${ }^{55,56}$ and applied ${ }^{57,58}$ research. When $\mathrm{TiO}_{2}$ is irradiated with photons of wavelength in the UV region, electron-hole pairs are produced: holes are powerful oxidants, electrons are good reducing agents and both rapidly react with adsorbates. ${ }^{59}$ Titanium dioxide is now playing a central role in the engineering of surfaces, ${ }^{60,61}$ in particular in the field of lithography. ${ }^{53,62}$ Here, we report for the first time improved access to micro-patterned polymer brushes using near-UV light titanium dioxide photocatalytic lithography.

Photocatalytic lithography was presently performed on lab-made substrates. We deposited transparent and mechanically robust $\mathrm{TiO}_{2}$ anatase films with high photoactivity on glass and silicon wafer (Fig. S3, ESI $\dagger$ ) from an acidic $\mathrm{TiO}_{2}$ sol using the electrochemicallyassisted technique, first reported by our group. ${ }^{63}$ The requirement of common lab instrumentation and the possibility to store and reuse 


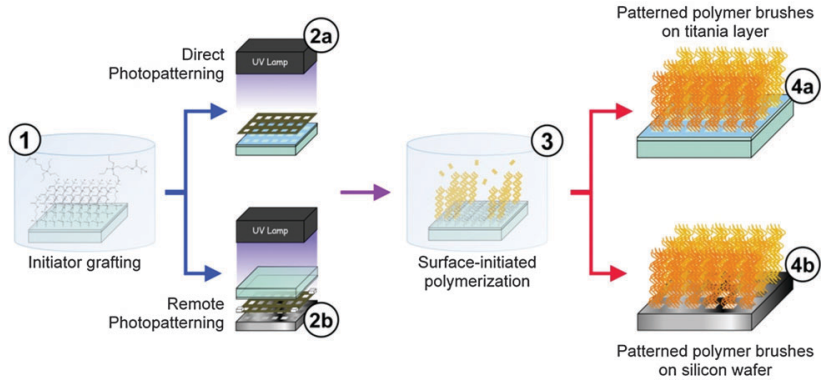

Fig. 1 Preparation of patterned brushes. Grafting of the ATRP initiator (1), pattern formation using both direct (2a) and remote (2b) photocatalytic lithography, SI-ATRP (3) and the obtained polymer patterns (4a, 4b).

the sol for up to one month have made this process highly appealing, cheap and scalable. In addition, the quality of the $\mathrm{TiO}_{2}$ film is comparably better in terms of smoothness ( $\mathrm{rms} 0.563 \mathrm{~nm}$ ) compared to those commonly obtained by dip-coating or spin-coating. ${ }^{64}$ Film thickness can be increased at will by repeating the deposition cycle. ${ }^{63}$ Films showed the typical increase in hydrophilicity upon exposure to $365 \mathrm{~nm}$ UV radiation due to enhanced hydroxyl surface termination (generally reported as "surface-induced hydrophilicity"65). We exploited this phenomenon to improve chemisorption of the atom transfer radical polymerization (ATRP) initiator (3-(2-bromoisobutyramido)propyl)triethoxysilane (BIB-APTES) ${ }^{66}$ on $\mathrm{TiO}_{2}$ (Fig. 1, step 1). Direct photocatalytic micropatterning of the initiator was achieved through UV-irradiation with $365 \mathrm{~nm}$ UV light from a halogen lamp using a TEM grid on the substrate as a photomask (Fig. 1, step 2a).

Photocatalytic degradation could be easily followed on dedicated substrates by water contact angle measurements (Fig. S4, ESI $\dagger$ ). The water contact angle for surfaces functionalized with BIB-APTES, stored in the dark, was $75^{\circ}$. After $1 \mathrm{~h}$ of irradiation, the $\theta_{\mathrm{w}}$ decreased to less than $15^{\circ}$ and the disappearance of nitrogen and bromine signals from the XPS spectra gave definitive evidence of complete deactivation of the initiator molecules (Table S1, ESI $\dagger$ ). On the other hand, BIB-APTES grafted on surfaces with no photoactivity, like silicon wafer or glass, was unaffected even after more than $5 \mathrm{~h}$ of UV irradiation as confirmed by the unchanged water contact angle and the ability to start the growth of polymer brushes. This confirmed the critical role of $\mathrm{TiO}_{2}$ in the photo-patterning of the initiator; a $365 \mathrm{~nm}$ lamp (working at $60 \mathrm{~mW}$ power density) does not allow photolysis of the adsorbates.

We used surface-initiated atom transfer radical polymerization (SI-ATRP), a controlled free radical polymerization process, to amplify the obtained initiator pattern into a poly(methyl methacrylate) (PMMA) brush. ${ }^{67,68}$ As a proof of concept, we chose the methyl methacrylate (MMA) monomer but, in principle, any ATRP-friendly monomer can be used. Activators regenerated by electron transfer (ARGET) ATRP was selected because, in contrast to classical ATRP, offers improved oxygen tolerance and permits the adoption of milder conditions. ${ }^{69}$ PMMA brush growth was carried out at $30{ }^{\circ} \mathrm{C}$ in a $4: 1 \mathrm{v} / \mathrm{v}$ methanol-water mixture using a $\mathrm{CuBr}_{2} /$ tris(2-pyridylmethyl)amine (TPMA) catalyst activated by an excess of ascorbic acid. Polymerization of BIB-APTES-functionalized substrates proceeded smoothly, leading to PMMA brushes with

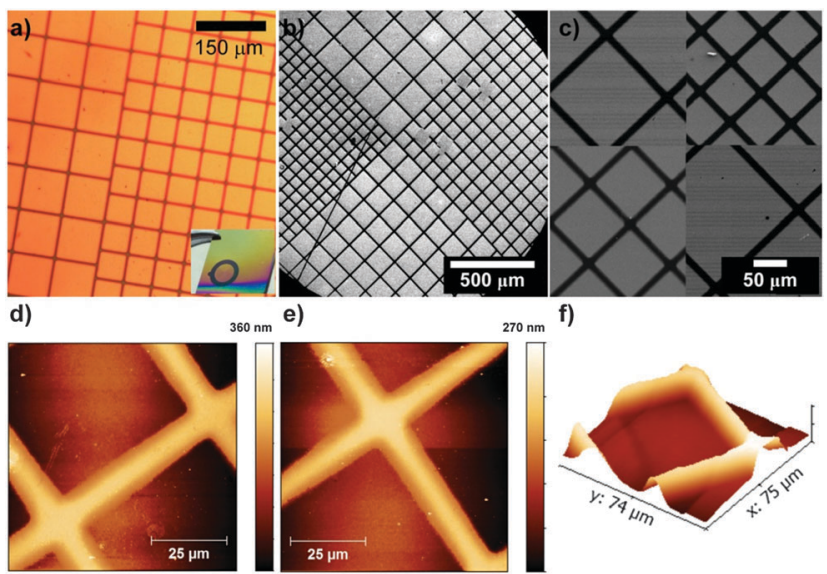

Fig. 2 Direct photocatalytic lithography of the initiator and subsequent SI-ATRP. Optical microscopy (a, inset: picture of the typical sample), scanning electron microscopy $(b, c)$ and atomic force microscopy (tapping mode, $d$, e and f) of the patterned surface.

thicknesses up to $200 \mathrm{~nm}$ depending upon the amount of time allowed for polymerization (Fig. S5, ESI $\dagger$ ). Successful grafting of polymer brushes was confirmed by water contact angle measurements $\left(68^{\circ}\right.$, which is consistent with previous wetting experiments with water on PMMA brushes ${ }^{70}$ ) and FTIR analysis (Fig. S6b, $\mathrm{ESI} \dagger$ ). The brush thickness is linearly correlated with polymerization time (over at least $8 \mathrm{~h}$ ) suggesting a good control of the polymerization (Fig. S5, ESI $\dagger$ ). Fig. 2 shows that the grid patterns have been successfully replicated onto the $\mathrm{TiO}_{2}$ surface and $10 \mu \mathrm{m}$ wide PMMA lines were obtained with very good resolution (see also Fig. S7, ESI $\dagger$ ). Remarkably, the brushes were able to restart the polymerization of MMA with excellent $(\geq 90 \%)$ reinitiation efficiency (Fig. S6a, ESI $\dagger$ ) and also allowed the formation of blockcopolymers: for example PMMA- $b$-PS brushes, with a PS block up to $80 \mathrm{~nm}$ thick, could be obtained by subsequent polymerization of styrene on a PMMA brush as shown by the increase in the contact angle (from $68^{\circ}$ to $90^{\circ}$, in accordance with literature findings ${ }^{71}$ ) and FTIR analysis (Fig. S6b and c, ESI $\dagger$ ).

Direct photocatalytic lithography could play a crucial role for innovation in the field of polymer brush micro-lithography. Nevertheless, the need of a $\mathrm{TiO}_{2}$ layer or, in general, of a photoactive substrate is limiting for many applications. Notwithstanding the smoothness, the transparency, the hardness and the biocompatibility of the titania layer, its photocatalytic properties could not be desired for some applications. The necessity to graft brushes directly onto a specific surface or onto substrates that cannot withstand thermal treatments (needed for the development of titania photoactivity) could occur. We found in remote photocatalysis a powerful solution for this general problem. The group of Fujishima, first, reported that the photooxidation of organic molecules can take place not only on the direct titanium dioxide surface but also on substrates placed at relatively considerable distances (up to $500 \mu \mathrm{m}$ ) from it. ${ }^{65,72}$ The mechanism of remote photocatalysis had been highly controversial until Kubo et al. ${ }^{73}$ demonstrated that $\mathrm{H}_{2} \mathrm{O}_{2}$ molecules, which are generated at the photocatalyst surface from atmospheric water and oxygen, migrate in the 
a)

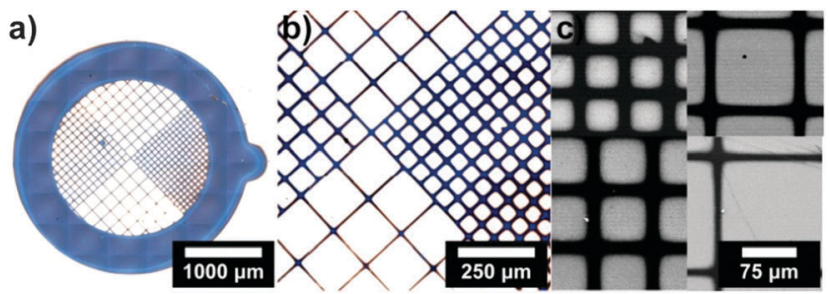

Fig. 3 Remote photocatalytic lithography of the initiator and subsequent SI-ATRP. Optical microscopy (a, b), scanning electron microscopy (c) of the patterned silica substrate.

surrounding air and are cleaved to $\mathrm{HO}^{\bullet}$ radicals in the exposed areas of the target surface. Such a mechanism is particularly useful to explain the high resolution pattern obtained. Highly oxidative radical species form only in the irradiated areas, avoiding lateral oxidation due to migration. ${ }^{74,75}$ Remote oxidation of organic contaminants, alkylsiloxane and thiol SAMs, polymers and metals has been reported, ${ }^{76,77}$ especially oriented to the generation of superhydrophilic/superhydrophobic patterns. ${ }^{75}$ Here, for the first time, we describe the successful application of remote photocatalytic lithography for the realization of patterned polymer brushes. This is potentially a universal approach, able to generate high resolution patterns on any kind of substrate. In order to obtain a good resolution, avoiding effects connected to the titania substrate morphology and light scattering ability, the quality of the photoactive layer is critical. Again, electrochemically-assisted titania deposition gave high performance in terms of transparency and smoothness (Fig. S3, ESI $\dagger$ ). Remote photocatalytic patterning was performed by irradiating with $365 \mathrm{~nm}$ UV light BIB-APTESfunctionalized silicon substrates through our titania-coated glass, pre-cleaned by UV irradiation for $1 \mathrm{~h}$, using a $100 \mu \mathrm{m}$-thick Teflon spacer (Fig. 1, step 2b). Micropatterning was achieved using a TEM grid and patterns were amplified with PMMA brushes, as already discussed for direct photolithography. The water contact angle decreased from $70^{\circ}$ to $33^{\circ}$ after $2 \mathrm{~h}$ irradiation of the initiatorfunctionalized substrate. In addition, as for the direct approach, XPS showed complete disappearance of the bromine signal (Table S1, ESI $\dagger$ ). Nevertheless, the best pattern resolution was achieved with an irradiation time of $5 \mathrm{~h}$. A complete optical and electron microscopic characterization is shown in Fig. 3 and Fig. S8, ESI $\dagger$.

To conclude, the growing excitement in the field of polymer brushes and the proved request for efficient patterning means urge the introduction of more facile and low-cost method to develop such architectures. Here, we discussed for the first time the use of photocatalytic lithography for making patterned polymer brushes, showing how innovative this approach could be. Titanium dioxide high photoactivity was employed to selectively degrade initiators of polymerization under near-UV irradiation through a photomask, and the obtained patterns were replicated by SI-ATRP. While direct photocatalytic lithography could be obtained only on the surface of a thin titania layer, the remote approach allowed us to achieve photocatalytic patterning on, virtually, any kind of substrate thanks to the migration of oxidizing species from a $\mathrm{TiO}_{2}$ interface. Both approaches lead to sharp edges and high line resolution. The remote approach is especially relevant being a general, non-invasive and highthroughput lithographic technique. We deliberately chose cheap materials (e.g. glass instead of quartz slides) to make it affordable to a wider spectrum of researchers. Long time irradiation was correlated with a low-energetic lithographic lamp (safe and simple to handle); in such a way, high resolution is simple to reach. In addition, our process can be scaled up to the wafer scale, with the future final goal to design controlled areas with different functionalities, useful for applications, e.g. in microfluidics and for the development of cell-responsive surfaces.

The authors want to express their gratitude to Dr L. Meda and Dr G. Marra (Research Center for Non-Conventional Energies, ENI Donegani Institute, Novara) for kindly providing the X-ray photoelectron spectroscopy (XPS) analyses, the scanning electron microscopy (SEM) images and X-ray diffraction (XRD) analyses, respectively. G.S. would like to thank Dr S. Hoeppener.

\section{Notes and references}

1 R. Barbey, L. Lavanant, D. Paripovic, N. Schüwer, C. Sugnaux, S. Tugulu and H.-A. Klok, Chem. Rev., 2009, 109, 5437-5527.

2 S. G. Boyes, A. M. Granville, M. Baum, B. Akgun, B. K. Mirous and W. J. Brittain, Surf. Sci., 2004, 570, 1-12.

3 O. Azzaroni, J. Polym. Sci., Part A: Polym. Chem., 2012, 50, 3225-3258.

4 T. Chen, I. Amin and R. Jordan, Chem. Soc. Rev., 2012, 41, 3280-3296.

5 M. E. Welch and C. K. Ober, J. Polym. Sci., Part B: Polym. Phys., 2013, 51, 1457-1472.

6 G. J. Dunderdale, J. R. Howse and J. P. A. Fairclough, Langmuir, 2011, 27, 11801-11805.

7 J. Cui, O. Azzaroni and A. del Campo, Macromol. Rapid Commun., 2011, 32, 1699-1703.

8 G. J. Dunderdale and J. P. A. Fairclough, Langmuir, 2013, 29, 3628-3635.

9 M. Singh, O. Odusanya, G. M. Wilmes, H. B. Eitouni, E. D. Gomez, A. J. Patel, V. L. Chen, M. J. Park, P. Fragouli, H. Iatrou, N. Hadjichristidis, D. Cookson and N. P. Balsara, Macromolecules, 2007, 40, 4578-4585.

10 C. R. Daniels, L. J. Tauzin, E. Foster, R. C. Advincula and C. F. Landes, J. Phys. Chem. B, 2013, 117, 4284-4290.

11 I. Tokareva, I. Tokarev, S. Minko, E. Hutter and J. H. Fendler, Chem. Commun., 2006, 3343-3345.

12 T. Chen, R. Ferris, J. Zhang, R. Ducker and S. Zauscher, Prog. Polym. Sci., 2010, 35, 94-112.

13 H. Ma, J. He, X. Liu, J. Gan, G. Jin and J. Zhou, ACS Appl. Mater. Interfaces, 2010, 2, 3223-3230.

14 H. C. McCaig, E. Myers, N. S. Lewis and M. L. Roukes, Nano Lett., $2014,14,3728-3732$.

15 C. Xu, X. Fu, M. Fryd, S. Xu, B. B. Wayland, K. I. Winey and R. J. Composto, Nano Lett., 2006, 6, 282-287.

16 S. Kumar, Y. L. Dory, M. Lepage and Y. Zhao, Macromolecules, 2011, 44, 7385-7393.

17 H. J. Snaith, G. L. Whiting, B. Sun, N. C. Greenham, W. T. S. Huck and R. H. Friend, Nano Lett., 2005, 5, 1653-1657.

18 G. Gunkel, M. Weinhart, T. Becherer, R. Haag and W. T. S. Huck, Biomacromolecules, 2011, 12, 4169-4172.

19 D. Falconnet, G. Csucs, H. M. Grandin and M. Textor, Biomaterials, 2006, 27, 3044-3063.

20 S. Peng and B. Bhushan, RSC Adv., 2012, 2, 8557.

21 F. Zhou and W. T. S. Huck, Phys. Chem. Chem. Phys., 2006, 8, 3815.

22 S. Dai, P. Ravi and K. C. Tam, Soft Matter, 2008, 4, 435.

23 A. Olivier, F. Meyer, J. Raquez, P. Damman and P. Dubois, Prog. Polym. Sci., 2012, 37, 157-181.

24 D. M. Jones and W. T. S. Huck, Adv. Mater., 2001, 13, 1256.

25 S. Santer, A. Kopyshev, H. Yang and J. Rühe, Macromolecules, 2006, 39, 3056-3064.

26 O. a. Guskova and C. Seidel, Macromolecules, 2011, 44, 671-682. 
27 S. Santer, A. Kopyshev, J. Donges, J. Rühe, X. Jiang, B. Zhao and M. Müller, Langmuir, 2007, 23, 279-285.

28 Y.-K. Lai, Z. Chen and C.-J. Lin, J. Nanoeng. Nanomanuf., 2011, 1, 18-34.

29 A. Ulman, Chem. Rev., 1996, 96, 1533-1554.

30 M. Geissler and Y. Xia, Adv. Mater., 2004, 16, 1249-1269.

31 Q. Liu, C. Wu, H. Cai, N. Hu, J. Zhou and P. Wang, Chem. Rev., 2014, 114, 6423-6461.

32 E. Menard, M. A. Meitl, Y. Sun, J. Park, D. J. Shir, Y. Nam, S. Jeon and J. A. Rogers, Chem. Rev., 2007, 107, 1117-1160.

33 Y. Li, J. Zhang, L. Fang, L. Jiang, W. Liu, T. Wang, L. Cui, H. Sun and B. Yang, J. Mater. Chem., 2012, 22, 25116.

34 T. Chen, D. P. Chang, R. Jordan and S. Zauscher, Beilstein J. Nanotechnol., 2012, 3, 397-403.

35 T. Chen, R. Jordan and S. Zauscher, Polymer, 2011, 52, 2461-2467.

36 Y. Tsujii, M. Ejaz, S. Yamamoto, T. Fukuda, K. Shigeto, K. Mibu and T. Shinjo, Polymer, 2002, 43, 3837-3841.

37 S. J. Ahn, M. Kaholek, W.-K. Lee, B. LaMattina, T. H. LaBean and S. Zauscher, Adv. Mater., 2004, 16, 2141-2145.

38 M. Kaholek, W. Lee, B. LaMattina, K. C. Caster and S. Zauscher, Nano Lett., 2004, 4, 373-376.

39 E. ul Haq, Z. Liu, Y. Zhang, S. a. A. Ahmad, L.-S. Wong, S. P. Armes, J. K. Hobbs, G. J. Leggett, J. Micklefield, C. J. Roberts and J. M. R. Weaver, Nano Lett., 2010, 10, 4375-4380.

40 X. Fan, L. Lin, J. L. Dalsin and P. B. Messersmith, Polym. Prepr., 2005, 46, 442-443.

41 J.-K. Chen, Z.-Y. Chen, H.-C. Lin, P.-D. Hong and F.-C. Chang, ACS Appl. Mater. Interfaces, 2009, 1, 1525-1532.

42 N. Herzer, S. Hoeppener and U. S. Schubert, Chem. Commun., 2010, 46, 5634-5652.

43 S. Hoeppener, R. Maoz and J. Sagiv, Nano Lett., 2003, 3, 761-767.

44 S. A. Ahmad, G. J. Leggett, A. Hucknall and A. Chilkoti, Biointerphases, 2011, 6, 8-15.

45 R. Iwata, P. Suk-In, V. P. Hoven, A. Takahara, K. Akiyoshi and Y. Iwasaki, Biomacromolecules, 2004, 5, 2308-2314.

46 S. Tugulu, M. Harms, M. Fricke, D. Volkmer and H.-A. Klok, Angew. Chem., Int. Ed., 2006, 45, 7458-7461.

47 O. P. Khatri, H. Sano, K. Murase and H. Sugimura, Langmuir, 2008, 24, 12077-12084.

48 M. Yamaguchi, K. Ikeda, M. Suzuki, A. Kiyohara, S. N. Kudoh, K. Shimizu, T. Taira, D. Ito, T. Uchida and K. Gohara, Langmuir, 2011, 27, 12521-12532.

49 S. Sun and G. J. Leggett, Nano Lett., 2007, 7, 3753-3758.

50 S. Nishimoto, A. Kubo, K. Nohara, X. Zhang, N. Taneichi, T. Okui, Z. Liu, K. Nakata, H. Sakai, T. Murakami, M. Abe, T. Komine and A. Fujishima, Appl. Surf. Sci., 2009, 255, 6221-6225.

51 Z. Xie, C. Chen, X. Zhou, T. Gao, D. Liu, Q. Miao and Z. Zheng, ACS Appl. Mater. Interfaces, 2014, 6, 11955-11964.
52 K. Nakata and A. Fujishima, J. Photochem. Photobiol., C, 2012, 13, 169-189.

53 K. Liu, M. Cao, A. Fujishima and L. Jiang, Chem. Rev., 2014, 114, 10044-10094.

54 H. Park, Y. Park, W. Kim and W. Choi, J. Photochem. Photobiol., C, 2013, 15, 1-20.

55 U. Diebold, Surf. Sci. Rep., 2003, 48, 53-229.

56 C. Marchiori, G. Di Liberto, G. Soliveri, L. Loconte, L. Lo Presti, D. Meroni, M. Ceotto, C. Oliva, S. Cappelli, G. Cappelletti, C. Aieta and S. Ardizzone, J. Phys. Chem. C, 2014, 118, 24152-24164.

57 K. Nakata, T. Ochiai, T. Murakami and A. Fujishima, Electrochim. Acta, 2012, 84, 103-111.

58 A. Antonello, G. Soliveri, D. Meroni, G. Cappelletti and S. Ardizzone, Catal. Today, 2014, 230, 35-40.

59 O. Carp, Prog. Solid State Chem., 2004, 32, 33-177.

60 G. Soliveri, R. Annunziata, S. Ardizzone, G. Cappelletti and D. Meroni, J. Phys. Chem. C, 2012, 116, 26405-26413.

61 G. Soliveri, D. Meroni, G. Cappelletti, R. Annunziata, V. Aina, G. Cerrato and S. Ardizzone, J. Mater. Sci., 2014, 49, 2734-2744.

62 Y. Paz, Beilstein J. Nanotechnol., 2011, 2, 845-861.

63 G. Maino, D. Meroni, V. Pifferi, L. Falciola, G. Soliveri, G. Cappelletti and S. Ardizzone, J. Nanopart. Res., 2013, 15, 2087.

64 Q. Xu, D. V. Wellia, M. A. Sk, K. H. Lim, J. S. C. Loo, D. W. Liao, R. Amal and T. T. Y. Tan, J. Photochem. Photobiol., A, 2010, 210, 181-187.

65 A. Fujishima, X. Zhang and D. Tryk, Surf. Sci. Rep., 2008, 63, 515-582.

66 X. He, W. Yang and X. Pei, Macromolecules, 2008, 41, 4615-4621.

67 K. Matyjaszewski, P. J. Miller, N. Shukla, B. Immaraporn, A. Gelman, B. B. Luokala, T. M. Siclovan, G. Kickelbick, T. Vallant, H. Hoffmann and T. Pakula, Macromolecules, 1999, 32, 8716-8724.

68 S. Edmondson, V. L. Osborne and W. T. S. Huck, Chem. Soc. Rev., 2004, 33, 14-22.

69 K. Matyjaszewski, H. Dong, W. Jakubowski, J. Pietrasik and A. Kusumo, Langmuir, 2007, 23, 4528-4531.

70 Y. Ma, X. Cao, X. Feng, Y. Ma and H. Zou, Polymer, 2007, 48, $7455-7460$

71 A. Samadi, S. M. Husson, Y. Liu, I. Luzinov and S. Michael Kilbey, Macromol. Rapid Commun., 2005, 26, 1829-1834.

72 T. Tatsuma, S. Tachibana, T. Miwa, D. A. Tryk and A. Fujishima, J. Phys. Chem. B, 1999, 103, 8033-8035.

73 W. Kubo and T. Tatsuma, J. Am. Chem. Soc., 2006, 128, 16034-16035.

74 T. Tatsuma, W. Kubo and A. Fujishima, Langmuir, 2002, 18, 9632-9634.

75 N. Blondiaux, S. Zürcher, M. Liley and N. D. Spencer, Langmuir, 2007, 23, 3489-3494.

76 T. Tatsuma, S. Tachibana and A. Fujishima, J. Phys. Chem. B, 2001, 105, 6987-6992.

77 W. Kubo, T. Tatsuma, A. Fujishima and H. Kobayashi, J. Phys. Chem. B, 2004, 108, 3005-3009. 